\title{
The association between the prevalence of restless leg syndrome, fatigue, and sleep quality in patients undergoing hemodialysis
}

Ayla C. Turk, MD, Sultan Ozkurt, MD, Ebru Turgal, MSc, Fusun Sahin, MD.

\section{ABSTRACT}

الأهداف : تحديد متلازمة تململ الساقين لمرضى القصور الكلوي

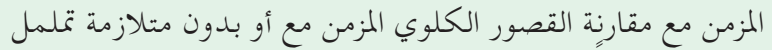

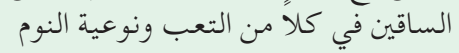

الطريقة : اشتملت هذه الدراسة المقطعية العرضية على 220 مريضاً

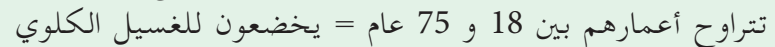

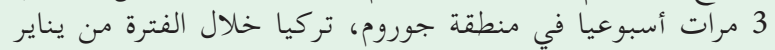

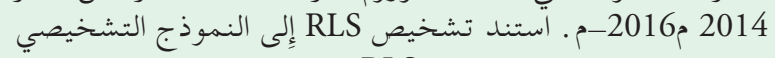

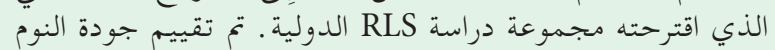

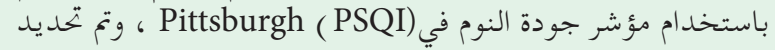

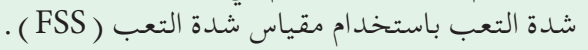

النتائج : من بين 16.8\% العد د=37 (المجموعة الأولى ) كانوا مصابين

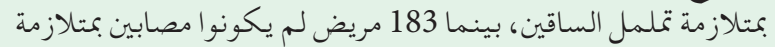

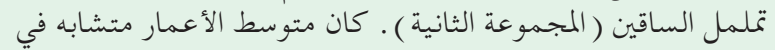

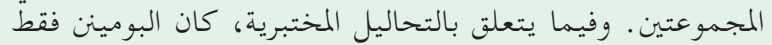

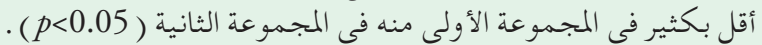

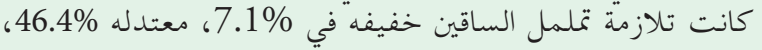

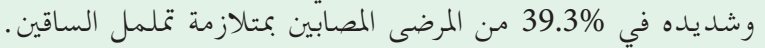
واشتملت التعوامل المرتبطة بشدة

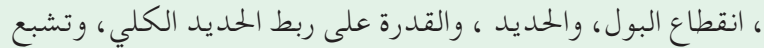

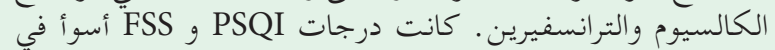
المجموعة الأولى ( الخكانس

الخاتمة: متلازمة تململ الساقين حالة شائعة عند المرضى الذئي

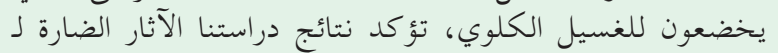
RLS

Objective: To determine the prevalence of restless legs syndrome (RLS) in patients with chronic renal failure (CRF) and to compare CRF patients with or without RLS in terms fatigue and sleep quality.

Methods: A cross-sectional study was conducted on 220 patients (18-75 years) who were undergoing dialysis 3 times weekly in Çorum Province, Corum, Turkey, between January 2014 and January 2016. The diagnosis of RLS was based on the diagnostic form proposed by the international RLS study group. Sleep quality was evaluated using the Pittsburgh sleep quality index (PSQI), and severity of fatigue was determined by using fatigue severity scale (FSS).

Results: Of all the participants, 16.8\% (n=37) (Group 1) were found to have RLS, while 183 patients had no RLS (Group 2). The mean ages were similar between groups. With respect to laboratory analyses, a $p$-value of $<0.05$ was considered in Group 1 than in Group 2 . Restless legs syndrome was mild (7.1\%), moderate (46.4\%) and severe (39.3\%) in patients with RLS. Factors associated with the severity of RLS included weight, duration of dialysis, anuria, iron, total iron binding capacity, calcium and transferrin saturation. The PSQI and FSS scores were significantly worse in Group $1(p<0.001)$.

Conclusion: Restless legs syndrome is a common condition in patients undergoing hemodialysis; the results of our study confirm the adverse effects of RLS in terms of many aspects of sleep quality and fatigue.

Saudi Med J 2018; Vol. 39 (8): 792-798

doi: 10.15537/smj.2018.8.22398

From the Department of Physical Medicine and Rehabilitation (Turk) from the Department of Biostatistics (Turgal), Faculty of Medicine, Hitit University, Corum; from the Department of Nephrology (Ozkurt), Faculty of Medicine, Osmangazi University, Eskisehir; and from the Department of Physical Medicine and Rehabilitation (Sahin), Faculty of Medicine, Pamukkale University, Denizli, Turkey.

Received 20th March 2018 Accepted 6th June 2018.

Address correspondence and reprint request to: Dr. Ayla C. Turk, Department of Physical Medicine and Rehabilitation, Faculty of Medicine, Hitit University, Corum, Turkey. E-mail: drayla1976@hotmail.com ORCID ID: orcid.org/0000-0002-0359-1710 
$\mathrm{R}$ estless legs syndrome (RLS) is a neurological sensory-motor disorder that is associated with reduced life quality and feelings of discomfort mostly occurring during sleeping hours. ${ }^{1,2}$ The condition is characterized by an urgent, uncontrollable need to move one's limbs that is accompanied by, or caused by, a peculiar, unpleasant sensation (paraesthesia). ${ }^{3}$ Moving the legs or walking usually eases the symptoms, which are generally more intense during the night hours and tend to occur at rest. ${ }^{2}$ Restless legs syndrome causes confusion and unrest which affects individual performance and family life; increases fatigue, sleep disturbance and stress; and reduces quality of life. ${ }^{4}$

Depending on the etiological factors, the disease is classified into primary and secondary forms. Most patients have the primary idiopathic form of the disease, in which a positive family history is present in nearly $40 \%$ of the cases, suggesting a genetic predisposition. 4,5

Secondary RLS mostly occurs in association with iron deficiency, while other conditions, such as peripheral neuropathy, diabetes mellitus (DM), multiple sclerosis, radiculopathy, rheumatoid arthritis, and renal failure may frequently co-exist with RLS. ${ }^{6,7}$ Also, RLS may develop as a secondary condition during the course of several diseases, such as Parkinsonism, rheumatic disease or during pregnancy. 17,8 Certain medications (antihypertensives, antidepressants, histamine receptor blockers) have also been reported to elicit RLS symptoms. ${ }^{5,9}$ Risk factors for RLS include advanced age, alcohol intake, smoking cigarettes, and caffeine intake. ${ }^{10,12}$

The prevalence of RLS varies across the world. In western countries, an estimated $8-15 \%$ of the general population experiences RLS; however, less than $5 \%$ of the Asian population is affected. ${ }^{13}$ A previous study in Turkey reported a prevalence rate of $3.19 \% .{ }^{14}$

The prevalence of RLS in chronic renal failure (CRF) patients requiring hemodialysis (HD) is higher than the general population and ranges from $6.6 \%-70 \% .^{13}$ Zaware et al reported that the prevalence of RLS in HD patients was $54.5 \%$ in their study on RLS and insomnia. ${ }^{4}$ In another study with 260 dialysis patients, Saraji et al found that the prevalence of RLS was $55 \%$, reporting a higher mean age and duration of dialysis for the RLS group. ${ }^{15}$ Dikici et al conducted a study on the

Disclosure. Authors have no conflict of interests, and the work was not supported or funded by any drug company. prevalence of RLS in Turkey, finding a rate of $45.9 \%$ as well as higher anxiety and insomnia in RLS patients.?

Restless legs syndrome is one of the leading causes of impaired quality of life in the general population. In HD patients, sleep disorders may lead to serious complications in the areas of mental health, general health, body pain, fatigue and physical functioning. The comorbidity of sleep disturbances and depression can cause severe consequences for HD patients. In addition, there are significant findings indicating that RLS and severe periodic limb-movement disorder are associated with increased mortality in HD patients. ${ }^{16,17}$

The objective of this study was to determine the prevalence of RLS in CRF patients undergoing HD in 2 separate centres of Corum province in Turkey. Also, secondary objectives included the comparison of demographic and biochemical characteristics as well as fatigue and sleep disturbance among CRF patients with or without RLS.

Methods. A total of 221 patients from 18-75 years of age undergoing dialysis 3 times weekly in 2 dialysis centres in Corum Province, Corum, Turkey were included. This cross-sectional study was carried out between January 2014 and January 2016, and the study protocol was approved by the Local Ethics Committee. The study was conducted according to the principles declaration of Helsinki, and all patients provided written informed consent prior to the study's initiation. All CRF patients over 18 years of age with a Kt/V ratio of greater than 1.4 (a marker of dialysis efficacy) were enrolled.

Age, duration of hemodialysis (months), concurrent systemic diseases (DM, hypertension, cardiac failure), cigarette smoking, coffee consumption, alcohol intake, haemoglobin, glucose, urea, creatinine, calcium, phosphorus, albumin, alkaline phosphatase, ferritin, parathyroid hormone, iron and total iron binding capacity (TIBC) were recorded. Transferrin saturation (TSAT) was estimated by dividing the iron level by the TIBC. For all biochemical analyses, sampling was performed 15 minutes prior to the dialysis session.

Restless legs syndrome diagnosis were based on the diagnostic form developed by the international RLS study group (IRLSSG). This form was originally developed in 1995, revised in 2002 and includes 4 criterias, all of which should be met in order to establish the diagnosis. ${ }^{18,19}$ These criteria are as follows: 1) urge to move extremities with paraesthesia/dysesthesia; 2) aggravation of symptoms with rest and reduction with physical activity; 3) inability to stand still and relief of symptoms with movement (walking, stretching, 
friction); 4) worsening of symptoms during evening and night-time. It was noted that symptoms began after dialysis treatment. The severity of RLS in the patients was assessed with the IRLSSG. Restless legs syndrome severity scale, developed on the basis of the questions proposed by the members of the IRLSSG. ${ }^{20}$ The RLS severity scale contains 10 questions, each scored from 0 (no effect of RLS) to 4 (very severe effect of RLS). The total score ranges from 0-40. Questions 1, 2, 3 and 6 are related with the severity of RLS, questions $7-8$ are related to the frequency and intensity of the symptoms, questions 4-5 the effects of RLS on sleep, and questions 9-10 measure the effect of RLS on the mood and daily social activities. According to scores; mild: 1-10 points, 11-20 points, moderate: $21-30$ points and severe and very severe RLS: 31-40 points.

The Pittsburgh sleep quality index (PSQI) was used to assess sleep quality. The PSQI was originally developed by Buysse et $\mathrm{al},{ }^{21}$ and the Turkish version was validated by Ağargün et al. ${ }^{22}$ The PSQI is a 19-item, self-reported scale that measures sleep quality and impairment over the previous month. In addition to these self-reported items, 5 questions are administered to the spouse or roommate of the patient (for a total of 24 questions). The 18 questions rated by the patient consist of 7 components: subjective sleep quality, sleep latency, sleep duration, habitual sleep activity, sleep disturbance, use of sleep medication, and daytime dysfunction. Each component is assigned 0-3 points. The scores in each of the 7 components are added up to the total score, which ranges from 0-21 points. A total score greater than 5 points indicates 'poor sleep quality'.

The fatigue severity scale (FSS) was used to assess fatigue symptoms, and the validity and reliability of the Turkish version was confirmed in a previous study. ${ }^{23}$ Using this 9-item scale, patients can assign each item a score between 1-7 ( $1=$ completely disagree, $7=$ completely agree), and the total score is the average of all 9 items. The cut-off score for pathological fatigue has been set at 4 points or higher, with lower scores indicating less fatigue. ${ }^{24}$

Statistical analysis. The data were summarized with descriptive statistics. The comparison of patients with or without RLS for data with normal distribution was performed using the Student's t-test, while data without normal distribution was compared using the Mann-Whitney U test. Categorical data were compared with Chi-square and Fisher's exact tests. The correlation between RLS and other parameters was assessed with Spearman's analysis. A multi-regression analysis was performed to identify the determinants of the severity of RLS. A logistic regression analysis was carried out to find the independent variables affecting RLS. A $p$-value $<0.05$ was considered statistically significant.

Results. Of the overall study group of 220 patients, $16.8 \%(\mathrm{n}=37)$ had RLS (Group 1), while 183 patients (83.2\%) did not have RLS (Group 2). The mean age of Group 1 was $59.31 \pm 0.91$ and in Group 2 was $61.51 \pm 1.76$ years, but there were no significant differences $(p>0.05)$. Also, both groups were comparable in terms of height, weight, body mass index (BMI), $\left(\mathrm{kg} / \mathrm{m}^{2}\right)$, age at onset of dialysis, duration of dialysis, concomitant diabetes and duration of diabetes and coexisting hypertension $(p>0.05)$. There were more smokers in Group 2. Table 1 presents the demographic characteristics of the patients.

Of all the laboratory parameters tested, a $p$-value of $<0.05$ was considered significant only in albumin in the RLS group; there were no significant differences in the other parameters (Table 2). Also, among the RLS patients, the severity of the disease was graded as mild $(7.1 \%)$, moderate $(46.4 \%)$, severe $(39.3 \%)$ and very severe $(7.1 \%)$. Weight, duration of dialysis, anuria, iron level, total iron binding capacity (TIBC), Calcium and ransferrin saturation (TSAT) were associated with the severity of RLS (Table 3).

There was a significant difference in PSQI scores between patients with RLS $(11.41 \pm 0.65)$ and those without RLS $(5.68 \pm 0.25)(p<0.001)$. Also, all PSQI sub-scale scores were significantly higher in RLS patients $(p<0.001)$. The percentage of patients reporting poor sleep quality was $91.9 \%$ among those with RLS versus $39.9 \%$ among those without RLS $(p<0.001)$. In the

Table 1 - Demographic data of 221 patients from 18-75 years of age undergoing dialysis 3 times weekly in 2 dialysis centres in Corum Province, Corum, Turkey.

\begin{tabular}{lccc}
\hline Variables & RLS (n=37) & No RLS(n=183) & $p$-value \\
\hline Gender F/M & $25 / 12$ & $87 / 96$ & $0.026^{\mathrm{c}}$ \\
Age & $61.51 \pm 1.76$ & $59.31 \pm 0.91$ & $0.312^{\mathrm{b}}$ \\
BMI & $25.99 \pm 1.29$ & $25.99 \pm 0.35$ & $0.997^{\mathrm{d}}$ \\
Age at first dialysis (year) & $54.35 \pm 2.04$ & $51.73 \pm 1.03$ & $0.288^{\mathrm{b}}$ \\
Duration of dialysis & $6.53 \pm 0.87$ & $7.8 \pm 0.44$ & $0.230^{\mathrm{b}}$ \\
Smoker (\%) & $28(75.7)$ & $144(62.3)$ & $0.814^{\mathrm{c}}$ \\
Alcohol intake (\%) & $0(100.0)$ & $3(1.6)$ & $1.000^{\mathrm{a}}$ \\
Coffee (\%) & $33(89.2)$ & $166(90.7)$ & $0.774^{\mathrm{a}}$ \\
Anuria (\%) & $12(32.4)$ & $90(49.1)$ & $0.062^{\mathrm{c}}$ \\
Diabetes mellitus (yes \%) & $21(56.8)$ & $114(62.3)$ & $0.580^{\mathrm{c}}$ \\
Duration of diabetes (year) & $9.95 \pm 2.29$ & $6.51 \pm 0.78$ & $0.162^{\mathrm{b}}$ \\
Hypertension (\%) & $13(35.1)$ & $86(47.0)$ & $0.186^{\mathrm{c}}$ \\
\hline
\end{tabular}

${ }^{\mathrm{a}}$ Fisher's exact test, ${ }^{\mathrm{b}}$ Independent $\mathrm{t}$ test, ${ }^{\mathrm{C}}$ Pearson $\chi^{\wedge} 2$ test,

${ }^{\mathrm{d}}$ Mann-Whitney U test. BMI - body mass index, RLS - restless legs syndrome 
Table 2 - Comparison of laboratory data in study groups.

\begin{tabular}{|c|c|c|c|}
\hline Laboratory data & RLS (n=37) & No RLS (n=183) & $p$-value \\
\hline $\mathrm{Hb}(\mathrm{g} / \mathrm{dl})$ & $14.48 \pm 2.93$ & $11.92 \pm 0.1$ & $0.512^{\mathrm{d}}$ \\
\hline Hct & $45.15 \pm 8.66$ & $36.21 \pm 0.33$ & $0.466^{\mathrm{d}}$ \\
\hline Iron & $54.89 \pm 3.06$ & $61.51 \pm 2.34$ & $0.443^{\mathrm{d}}$ \\
\hline TIBC & $214.57 \pm 8.81$ & $207.33 \pm 4.07$ & $0.447^{d}$ \\
\hline TSAT & $25.08 \pm 1.80$ & $28.18 \pm 1.05$ & $0.283^{\mathrm{d}}$ \\
\hline TSAT < $20(\%)$ & $21(56.8)$ & $115(62.8)$ & $0.192^{\circ}$ \\
\hline Ferritin & $644.97 \pm 50.24$ & $631.20 \pm 25.30$ & $0.821^{\mathrm{b}}$ \\
\hline CRP & $20.83 \pm 5.82$ & $11.17 \pm 1.10$ & $0.112^{\mathrm{b}}$ \\
\hline Albumin & $4.12 \pm 0.02$ & $5.04 \pm 0.97$ & $0.044^{\mathrm{d}}$ \\
\hline $\mathrm{Ca}$ & $11.39 \pm 2.55$ & $8.86 \pm 0.07$ & $0.968^{d}$ \\
\hline $\mathrm{P}$ & $5.76 \pm 0.93$ & $5.07 \pm 0.07$ & $0.338^{d}$ \\
\hline PTH & $379.39 \pm 39.63$ & $389.06 \pm 21.05$ & $0.843^{b}$ \\
\hline ALP & $136.13 \pm 10.82$ & $150.99 \pm 6.71$ & $0.339^{\mathrm{b}}$ \\
\hline Glucose & $122.26 \pm 11.18$ & $113.51 \pm 4.66$ & $0.443^{b}$ \\
\hline URR & $76.48 \pm 0.74$ & $75.03 \pm 0.45$ & $0.215^{\mathrm{d}}$ \\
\hline $\mathrm{Kt} / \mathrm{V}$ & $1.74 \pm 0.05$ & $2.84 \pm 1.20$ & $0.668^{\mathrm{b}}$ \\
\hline \multicolumn{4}{|c|}{$\begin{array}{l}\text { '} \text { Independent } \mathrm{t} \text { test, }{ }^{\mathrm{c} P e a r s o n} \chi^{\wedge} 2 \text { test, }{ }^{\mathrm{d}} \text { Mann-Whitney } \mathrm{U} \text { test. } \\
\text { Kt/V: Laboratory indicators of dialysis dosage } \\
\mathrm{Hb} \text { - hemoglobin, Hct - hematocrit, TIBC - total iron binding capacity, } \\
\text { TSAT - transferrin saturation, CRP - C reactive protein, Ca - calcium, P - } \\
\text { phosphate, PTH - parathormon, ALP - alkaline phosphatase, URR - urea } \\
\text { reduction rate. }\end{array}$} \\
\hline
\end{tabular}

overall group, a significant positive correlation between PSQI and age (r: $0.188, p<0.005)$ and age at first dialysis ( $\mathrm{r}: 0.141, p<0.05$ ) was observed; in the RSL patients, PSQI was significantly and positively correlated with the duration of diabetes ( $\mathrm{r}: 0.468, p<0.05)$ and fatigue (r: $0.325, p<0.05$ ).

The mean FSS scores in Groups 1 was $48.3 \pm 2.29$ and $39.75 \pm 1$ in Group $2,{ }^{18}$ with a significant difference between the 2 groups $(p<0.05)$ (Table 4). Fatigue correlated with sleep latency $(\mathrm{r}: 0.456, p<0.05)$ and daytime dysfunction ( $\mathrm{r}: 0.401, p<0.05$ ). The 2 groups were not significantly different with respect to the cause of CRF.

A logistic regression analysis, in which the presence of RLS was included as a dependent variable, was performed in order to determine the independent factors that had an impact on the risk of RLS. In multivariate logistic regression analyses, only the CRP value emerged as an independent factor for the development of RLS. In the univariate logistic regression analyses, gender, ferritin and CRP were independent factors for the development of RLS (Tables 5 \& 6).

Discussion. Based on the results of our study, 16.8\% of CRF patients had RLS. There were significantly more smokers among the RLS patients than among patients without RLS. Furthermore, sleep disturbance and
Table 3 - Factors affecting restless legs syndrome severity scale.

\begin{tabular}{|c|c|c|c|c|}
\hline \multirow[t]{2}{*}{ Variables } & \multicolumn{3}{|c|}{ Multivariate regression analysis } & \multirow[t]{2}{*}{$95 \% \mathrm{CI}$} \\
\hline & $\beta$ & SE & p-value & \\
\hline Constant & 56.333 & 13.024 & 0.000 & $29.072-83.593$ \\
\hline Weight & -0.256 & 0.073 & 0.002 & $-0.409--0.103$ \\
\hline $\begin{array}{l}\text { Duration of } \\
\text { dialysis }\end{array}$ & -0.522 & 0.158 & 0.004 & $-0.852--0.192$ \\
\hline Anuria & 4.218 & 2.012 & 0.050 & $0.007-8.430$ \\
\hline Iron & -0.556 & 0.198 & 0.011 & $-0.970--0.142$ \\
\hline TIBC & 0.197 & 0.047 & 0.001 & $0.098-0.296$ \\
\hline $\mathrm{Ca}$ & -5.736 & 1.304 & 0.000 & $-8.465--3.007$ \\
\hline TSAT & 0.938 & 0.365 & 0.019 & $0.174-1.702$ \\
\hline CRP & -0.082 & 0.041 & 0.059 & $-0.168-0.003$ \\
\hline
\end{tabular}

Table 4 - Sleep and fatigue scale by groups.

\begin{tabular}{lrcc}
\hline Variables & RLS (n=37) & No RLS $(n=183)$ & $p$-value \\
\hline PSQI & $11.41 \pm 0.65$ & $5.68 \pm 0.25$ & $<0.001^{\mathrm{d}}$ \\
Poor sleep quality (no \%) & $3(8.1)$ & $111(60.7)$ & $<0.001^{\mathrm{c}}$ \\
Subjective sleep quality & $1.62 \pm 0.12$ & $0.93 \pm 0.05$ & $<0.001^{\mathrm{d}}$ \\
Sleep latency & $2.7 \pm 0.27$ & $1.66 \pm 0.11$ & $<0.001^{\mathrm{d}}$ \\
Sleep duration & $1.43 \pm 0.21$ & $0.61 \pm 0.06$ & $<0.001^{\mathrm{d}}$ \\
Habitual sleep activity & $1.70 \pm 0.20$ & $0.47 \pm 0.06$ & $<0.001^{\mathrm{d}}$ \\
Sleep disturbance & $1.84 \pm 0.09$ & $1.21 \pm 0.04$ & $<0.001^{\mathrm{d}}$ \\
Use of sleep medication & $0.92 \pm 0.19$ & $0.31 \pm 0.06$ & $<0.001^{\mathrm{d}}$ \\
Daytime dysfunction & $1.19 \pm 0.16$ & $0.50 \pm 0.06$ & $<0.001^{\mathrm{d}}$ \\
Fatigue scale & $48.3 \pm 2.29$ & $39.75 \pm 1.18$ & $0.003^{\mathrm{d}}$ \\
\hline
\end{tabular}

'Pearson $\chi^{\wedge} 2$ test, ${ }^{\mathrm{d}}$ Mann-Whitney $U$ test.

PSQI - pittsburgh sleep quality index, RLS - restless legs syndrome.

fatigue were more common in CRF patients with RLS than those without RLS. Being female, a low ferritin level and elevated CRP levels were associated with an increased likelihood of RLS.

Identification of RLS in patients undergoing dialysis is clinically important, as the presence of RLS has been found to be associated with a significantly increased rate of cardiovascular risk and mortality. ${ }^{12}$ Additionally, RLS was reported to be related to low quality of life and increased risk of death in dialysis patients. ${ }^{16}$

Globally, the reported prevalence of RLS in dialysis patients varies significantly from $6.6 \%$ to $70 \% .4,13,15$ Patients with RLS are more likely to have diabetes and hypertension, ${ }^{7}$ and they are more likely to be female. ${ }^{8}$ However, some other studies failed to observe a link 
Table 5 - Factors affecting the presence of RLS.

\begin{tabular}{lccc}
\hline Variables & \multicolumn{3}{c}{ Univariate logistic regression analysis } \\
& OR & $95 \%$ CI & $P$-value \\
\hline Gender & 0.435 & {$[0.206-0.918]$} & 0.029 \\
PSQI & 1.402 & {$[1.261-1.559]$} & $<0.001$ \\
Fatigue scale & 1.038 & {$[1.012-1.065]$} & 0.004 \\
Ferritine & 1.002 & {$[1.000-1.003]$} & 0.009 \\
CRP & 1.021 & {$[1.021-1.039]$} & 0.020
\end{tabular}

PSQI - pittsburgh sleep quality index, CRP - C reactive protein, OR odds ratio, CI - confidence interval.

Table 6 - Factors affecting the presence of RLS.

\begin{tabular}{lccc}
\hline Variables & \multicolumn{3}{c}{ Multivariate logistic regression analysis } \\
& OR & $95 \%$ CI & P-value \\
\hline Constant & 0.069 & & 0.040 \\
Age & 1.022 & {$[0.987-1.058]$} & 0.215 \\
BMI & 0.983 & {$[0.916-1.056]$} & 0.642 \\
CRP & 1.019 & {$[1.001-0.037]$} & 0.034 \\
\hline \multicolumn{3}{c}{ BMI - body mass index, CRP - C reactive protein, OR - odds ratio, } \\
\multicolumn{4}{c}{ CI - confidence interval. -2log likelihood = 165.433 } \\
\hline \multicolumn{4}{c}{}
\end{tabular}

between diabetes, hypertension, gender, and RLS. ${ }^{12,25}$

In Turkey, similar to the global figures, the reported frequency of RLS among CRF patients ranges from percentages as low as $3.19 \%,{ }^{14}$ to percentages as high as $45.9 \% .^{9}$ In the current study, $16.8 \%$ of our CRF patients had RLS, with the incidence higher among female subjects.

With regard to symptoms, it is noteworthy to observe that severe symptoms have been reported in a significant proportion of RLS patients, such as $36.1 \%$ in one study, ${ }^{12}$ and $40.2 \%,{ }^{13}$ in another. Similar to the published data, $46.4 \%$ of our CRF patients with RLS had severe to very severe symptoms. Again, based on our results, weight, duration of dialysis, anuria, iron, TIBC, calcium and TSAT were associated with RLS symptom severity. Furthermore, the scores in the RLS severity scale correlated with sleep disturbance.

Many previous studies found a more increased incidence of comorbid conditions, such as DM and hypertension, in dialysis patients with RLS than in those without RLS, 7,13,15 while one study failed to identify such a relationship. ${ }^{12}$ In our study, the 2 groups had comparable rates of hypertension and diabetes. According to our analyses, cigarette smoking and coffee consumption were not associated with RLS in CRF patients. However, it should be noted that controversial results have been obtained in previous studies examining the association between RLS and cigarette smoking and coffee consumption, with some studies reporting an association, ${ }^{11,15}$ as compared to those finding no such association. ${ }^{12}$ Again, tea consumption was found to be unrelated to the development of RLS as was found in another study. ${ }^{15}$

In a study involving HD patients, in addition to a significant association between iron deficiency anemia and RLS, the subgroup of subjects with RLS were also found to have significantly lower hemoglobin levels. ${ }^{6}$ Conversely, other authors could not observe any associations of RLS with iron deficiency or anemia., ${ }^{8,12}$ It has also been found that iron deficiency, even in the absence of anemia, may lead to RLS (Scherer). While Saraji et al did not observe any relationship between serum ferritin and RLS, they did detect an association with serum hemoglobin. ${ }^{15}$ Although laboratory parameters in the 2 groups of our study were comparable other than for albumin, ferritin levels emerged as a determinant of the presence of RLS. Moreover, with respect to a variety of laboratory parameters, Zaware et $\mathrm{al}^{4}{ }^{4}$ did not find any associations of RLS with age, urea, creatinine, calcium, potassium, phosphorus, iron or ferritin, while Araujo et al, ${ }^{26}$ found that RLS patients had lower hemoglobin, albumin and alkaline phosphatase. A positive association with phosphate was reported in one study, with opposite findings in another. ${ }^{3,13}$ In the present study, only albumin levels were significantly lower among RLS patients, and despite lower iron levels, the difference was not significant. Because a reduced albumin level may represent a state of malnutrition, the levels of the albumin could be low in HD and also RLS patients. ${ }^{27}$ Ferritin was also comparable, although it was an independent factor for the development of RLS.

Sleep disorder is a common finding in patients with chronic renal failure, affecting 40\%-61\%. ${ }^{12,16}$ Restless legs syndrome has been reported to represent an important cause of sleep disturbance and disease morbidity in this population. ${ }^{4}$ Lin et al, ${ }^{13}$ reported that HD patients with RLS have higher PSQI scores and lower sleep quality. Difficulty in sleep-onset in patients with RLS was greater than non- RLS group (sleep latency more than 60 minutes: $52.1 \%$ versus $45.1 \%$ ). Sleep disturbance was more severe in RLS group (34.6\% versus $16.8 \%$ ). Daytime dysfunction was also greater in RLS group (6.3\% versus $0.7 \%) .{ }^{13}$ Zaware et $\mathrm{al}^{4}$ reported a significant relationship between RLS and insomnia severity index. Rohani et al found that sleep disturbance was $88 \%$ in dialysis patients with RLS. In the same study, short sleep duration, insomnia, use of sleep medications and daytime insomnia were found more frequently in patients with RLS. ${ }^{12}$ Female RLS patients experienced a more pronounced reduction in 
sleep quality, while male patients with RLS had more daytime sleepiness. ${ }^{5}{ }^{26}$ In our study, $91.9 \%$ of our RLS patients had poor sleep quality, as compared to $39.9 \%$ in those without RLS (PSQI >5). Also, patients with RLS had worse PSQI sub-scale scores (subjective sleep quality, sleep latency, sleep duration, habitual sleep activity, sleep disturbance, use of sleep medications and daytime dysfunction).

Published studies examining fatigue in CRF patients with RLS are scarce. In a study by Giannak et $\mathrm{al}^{28}$ involving 85 dialysis patients, RLS patients reported more severe fatigue, with positive correlations between the RLS severity scale and the fatigue index. When one considers that many HD patients experience intense fatigue symptoms, ${ }^{29}$ it becomes clear that effective treatment of RLS, which contributes to fatigue symptoms, may help reduce the severity of fatigue. ${ }^{28} \mathrm{On}$ the other hand, despite the presence of studies reporting the positive effects of exercise training on fatigue in HD patients, none specifically investigated patients with RLS. ${ }^{29}$ Future studies may provide valuable insights on the effects of exercise in uremic patients with RLS. In our study, RLS patients reported higher levels of fatigue, which were also associated with sleep latency and daytime dysfunction.

In conclusion, RLS is a prevalent condition in patients undergoing HD, and the results of this study appear to confirm that RLS has adverse effects on sleep quality and fatigue. Further studies are warranted to examine the long-term effects of interventions targeting sleep disturbance and fatigue in uremic RLS patients in order to determine their contribution to quality of life in this group of subjects.

Acknowledgment. We would like to thank Scribendi (www.scribendi.com) for English language editing.

\section{References}

1. Novak M, Winkelman JW, Unruh M. Restless legs syndrome in patients with chronic kidney disease. Semin Nephrol 2015; 35: 347-358.

2. Stefanidis I, Vainas A, Giannaki CD, Dardiotis E, Spanoulis A, Sounidaki M, et al. Restless legs syndrome does not affect 3-year mortality in hemodialysis patients. Sleep Med 2015; 16 : 1131-1138.

3. Giannaki CD, Hadjigeorgiou GM, Karatzaferi C, Pantzaris MC, Stefanidis I, Sakkas GK. Epidemiology, impact, and treatment options of restless legs syndrome in end-stage renal disease patients: an evidence-based review. Kidney Int 2014; 85: 1275-1282.

4. Hasheminasab Zaware R, Mahmoodi Meymand MH, Rezaeian M, Mohammadi Kamalabadi N, Mostafavi SA, Abdolkarimi Dawarani MA, et al. Insomnia and restless leg syndrome in patients undergoing chronic hemodialysis in Rafsanjan Ali Ibn Abitaleb hospital. Nephrourol Mon 2016; 8: e29527.
5. Scherer JS, Combs SA, Brennan F. Sleep disorders, restless legs syndrome, and uremic pruritus: diagnosis and treatment of common symptoms in dialysis patients. Am J Kidney Dis 2017; 69: 117-128.

6. Mao S, Shen H, Huang S, Zhang A. Restless legs syndrome in dialysis patients: a meta-analysis. Sleep Med 2014; 15: 1532-1538.

7. Stolic RV, Trajkovic GZ, Jekic D, Sovtic SR, Jovanovic AN, Stolic DZ, et al. Predictive parameters of survival in hemodialysis patients with restless leg syndrome. Saudi J Kidney Dis Transpl 2014; 25: 974-980.

8. Stefanidis I, Vainas A, Dardiotis E, Giannaki CD, Gourli P, Papadopoulou D, et al. Restless legs syndrome in hemodialysis patients: an epidemiologic survey in Greece. Sleep Med 2013; 14: 1381-1386.

9. Dikici S, Bahadir A, Baltaci D, Ankarali H, Eroglu M, Ercan N, et al. Association of anxiety, sleepiness, and sexual dysfunction with restless legs syndrome in hemodialysis patients. Hemodial Int 2014; 18: 809-818.

10. Symvoulakis E, Anyfantakis D, Lionis C. Restless legs syndrome: literature review. Sao Paulo Med J 2010; 128: 167-170.

11. Chu L, Chu E, Dogra G, Chakera A. Restless legs syndrome: an underappreciated and distressing problem for haemodialysis patients. Intern Med J 2014; 44: 1030-1033.

12. Rohani M, Aghaei M, Jenabi A, Yazdanfar S, Mousavi D, Miri S. Restless legs syndrome in hemodialysis patients in Iran. Neurol Sci 2015; 36: 723-727.

13. Lin CH, Wu VC, Li WY, Sy HN, Wu SL, Chang CC, et al. Restless legs syndrome in end-stage renal disease: a multicenter study in Taiwan. Eur J Neurol 2013; 20: 1025-1031.

14. Sevim S, Dogu O, Camdeviren H, Bugdayci R, Sasmaz T, Kaleagasi H, et al. Unexpectedly low prevalence and unusual characteristics of RLS in Mersin, Turkey. Neurology 2003; 61: 1562-1569.

15. Zadeh Saraji N, Hami M, Boostani R, Mojahedi MJ. Restless leg syndrome in chronic hemodialysis patients in Mashhad hemodialysis centers. J Renal Inj Prev 2016; 6: 137-141.

16. Unruh ML, Levey AS, D’Ambrosio C, Fink NE, Powe NR, Meyer KB. Restless legs symptoms among incident dialysis patients: association with lower quality of life and shorter survival. Am J Kidney Dis 2004; 43: 900-909.

17. Kraus MA, Fluck RJ, Weinhandl ED, Kansal S, Copland M, Komenda P, et al. Intensive hemodialysis and health-related quality of life. Am J Kidney Dis 2016; 68: S33-S42.

18. Walters AS. Toward a better definition of the restless legs syndrome. The international restless legs syndrome study group. Mov Disord 1995;10: 634-642.

19. Allen RP, Picchietti D, Hening WA, Trenkwalder C, Walters AS, Montplaisi J. Restless legs syndrome: diagnostic criteria, special considerations, and epidemiology. A report from the restless legs syndrome diagnosis and epidemiology workshop at the National Institutes of Health. Sleep Med 2003; 4: 101-119.

20. Walters AS, LeBrocq C, Dhar A, Hening W, Rosen R, Allen $\mathrm{RP}$, et al. Validation of the international restless legs syndrome study group rating scale for restless legs syndrome. Sleep Med 2003; 4: 121-132.

21. Buysse DJ, Reynolds CF, Monk TH, Berman SR, Kupfer DJ. TThe Pittsburgh sleep quality index: a new instrument for psychiatric practice and research. Psychiatry Res 1989; 28: 193-213. 
22. Agargun MY, Kara H, Anlar O. The Validity and Reliability of the Pittsburgh Sleep Quality Index. Turk Psikiyatri Derg 1996; 7: 107-111

23. Armutlu K, Korkmaz NC, Keser I, Sumbuloglu V, Akbiyik DI, Guney Z, et al. The validity and reliability of the fatigue severity scale in turkish multiple sclerosis patients. Int J Rehabil Res 2007; 30: 81-85.

24. Krupp LB, LaRocca NG, Muir-Nash J, Steinberg AD. The fatigue severity scale. Application to patients with multiple sclerosis and systemic lupus erythematosus. Arch Neurol 1989; 46: 1121-1123.

25. Tekdöş Demircioğlu D, Kavadar G, Esen Öre Ö, Emre TY, Yaka U. Relationship between restless leg syndrome and quality of life in uremic patients. Agri 2015; 27: 73-78.
26. Araujo SM, de Bruin VM, Nepomuceno LA, Maximo ML, Daher Ede F, Correia Ferrer DP, et al. Restless legs syndrome in end-stage renal disease: Clinical characteristics and associated comorbidities. Sleep Med 2010; 11: 785-790.

27. La Manna G, Pizza F, Persici E, Baraldi O, Comai G, Cappuccilli ML, et al. Restless legs syndrome enhances cardiovascular risk and mortality in patients with end-stage kidney disease undergoing long-term haemodialysis treatment. Nephrol Dial Transplant 2011; 26: 1976-1983.

28. Giannaki CD, Hadjigavriel M, Lazarou A, Michael A, Damianou L, Atmatzidis E, et al. Restless legs syndrome is contributing to fatigue and low quality of life levels in hemodialysis patients. World J Nephrol 2017; 6: 236-242.

29. Bossola M, Vulpio C, Tazza L. Fatigue in chronic dialysis patients. Semin Dial 2011; 24: 550-555. 